- Communication-

\title{
Electrochemical Oxygen Demand as a New Measure for Organic Pollutants
}

\author{
Sotaro ITO*, Toshiko YAMAGUCHI ${ }^{\dagger}$, Kazuo SASAKI, \\ Masahide YAMAGUCHI and Eiji SHOTO ${ }^{\dagger+}$
}

Received January 22, 1991 ; Accepted March 29, 1991

\section{INTRODUCTION}

Total organic carbon (TOC), biochemical oxygen demand (BOD) and chemical oxygen demand (COD) are typical nonspecific measures for organic pollutants in environments ${ }^{1)}$. TOC is equal to the analytical concentration of carbon atoms contained in organic pollutants, while BOD measures the extent of biological oxidation of organic pollutants and is time-dependent.

It is not clear whether COD represents the analytical concentration of organic materials in terms of oxygen equivalent. Much effort has been done to increase the extent of oxidation of organic pollutants in the determination of COD. The use of a strong oxidant at an elevated temperature increases the extent of oxidation and decreases the difference between $C O D$ and TOC. In a previous work ${ }^{2}$ ), the kinetic nature of $C O D$ determined by the permanganate method at $100^{\circ} \mathrm{C}$ was elucidated. Though the COD method is widely used to examine the water quality, there are several disadvantages such as the interference by chloride ions, time-consuming titration work, and production of a large amount of waste water containing heavy metal ions and concentrated acid(s).

* Department of Applied Chemistry, Faculty of Engineering, Hiroshima University, Higashi-hiroshima 724, † Department of Civil Engineering, ++ Institute for Wastewater Treatment.

Key words : Sewage, Chemical oxygen demand, Electrochemical oxygen demand, Chloride ion
In this communication, we propose a new measure for organic pollutants, Electrochemical Oxygen Demand (EOD), which is defined as oxygen equivalent of organic materials oxidized on a glassy carbon anode under controlled electrochemical conditions, as anew measure for organic pollutants.

\section{EXPERIMENTAL.}

The standard solution of $12.5 \mathrm{mM}$ sodium oxalate was purchased from Katayama Kagaku Kougyou Co. The sewage was obtained from the Wastewater Treatment Plant of Higashihiroshima.

The apparatus for the measurement of EOD is essentially an HPLC system (Shimadzu Chromatograph LC-6A and Shimadzu System Controller SCL-6A) with an electrochemical detector, but without a separation column. Into a flow of solvent (water containing $50 \mathrm{mM}$ sodium sulfate) at a flow rate of $1.6 \mathrm{ml} \mathrm{min}-1$ was injected $30-500 \mu 1$ of a sample solution with a Shimadzu Auto Injector SIL-6A. By use of a potentiostat (Hokuto Denko HA-301), the potential (vs. $\mathrm{Ag} / \mathrm{AgC1}$ reference electrode) of the glassy carbon anode in an electrolytic flow-cell (Yanagimoto DC-1) was controlled. The anodic current was recorded with a integrator (Shimadzu Chromatopac C-R3A).

Sodiun sulfate was added to all the sample solutions at a concentration of $50 \mathrm{mM}$ solution.

\section{Results and Discussion}

\subsection{Flow rate}

When 30-500 $\mu 1$ of a sample (sewage) was 
injected to the flow system, the anodic current was generated as a peak similar to that in HPLC. A sharp peak was observed at flow rates of $1.6-6.4 \mathrm{ml} \mathrm{min} \mathrm{mil}^{-1}$, while the peak was broader at $0.1-0.4 \mathrm{ml} \mathrm{min}^{-1}$. The flow rate was fixed to $1.6 \mathrm{ml} \mathrm{min}^{-1}$ in the following experiments.

\subsection{Anode potential}

The peak area thus obtained was dependent on the anode potential as shown in Fig. I. Since the chloride ion is electrochemically inert below $1.0 \mathrm{~V}$ (vs. Ag/ AgCl electrode), the sample electrolysis was done under a controlled potential from 0.8 to $1.0 \mathrm{~V}$.

\subsection{Unit of EOD}

The current peak area for various concentrations of sodium oxalate, which is used as a standard for COD by the permanganate method 3 ), is proportional to the square root of its concentration. Since the oxygen equivalent of $12.5 \mathrm{mM}$ sodium oxalate is $200 \mathrm{ppm}$, the unit of Electrochemical Oxygen Demand (EOD) was tentatively defined as follows: EOD (ppm) of a sample is equal to the oxygen equivalent of a solution of sodium oxalate which gives the same peak area as that of the

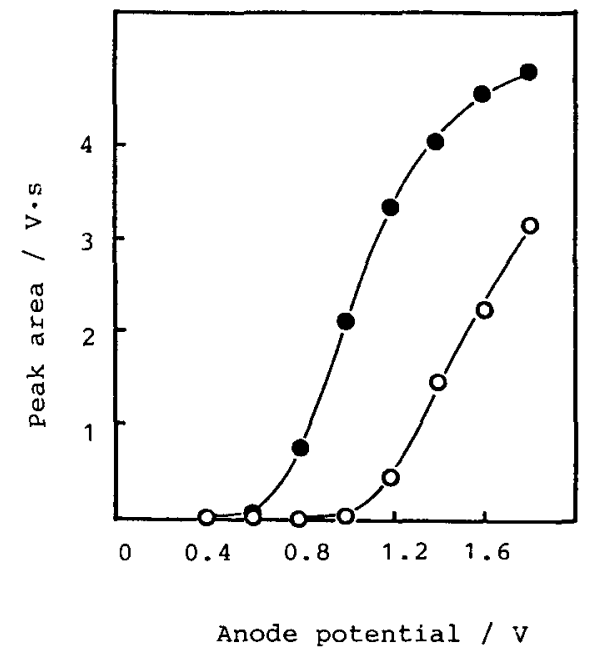

Fig. 1 Effect of anode potential on current peak area ${ }^{4)}$ for chloride ions (O) and sewage (O). sample solution. In Table 1, the values of EOD for several samples are listed with the COD by the permanganate method. 3

Table 1. EOD and COD for several samples

\begin{tabular}{lccc}
\hline \multicolumn{1}{c}{ Sample } & COD/ppm & EOD/ppm \\
\hline Phenol & $(1 \mathrm{mM})$ & 187 & 635 \\
Glucose $\quad(1 \mathrm{mM})$ & 108 & 0.0 \\
NaCl $\quad(60 \mathrm{mM})$ & 11.5 & 0.0 \\
Sodium oxalate & 200 & 200 \\
& $(12.5 \mathrm{mM})$ & & 39.4 \\
Sewage & 23.8 & \\
\hline
\end{tabular}

Glucose and chloride ions are inactive for the electrochemical oxidation, while phenol is more active for the electrochenical oxidation than for the permanganate oxidation. The EOD for sewage is comparable to the COD. The relative standard deviation for 10 measurements of EOD for the sewage was less than $4 \%$.

\subsection{Advantages of EOD over COD}

EOD can be rapidly determined with no interference from chloride ions and without producing a large amount of wastewater.

\section{References and Note}

1) A. E. Greenberg, R. R. Trussell and L. S. Clesceri (ed.), Standard Method for the Examination of Water and Wastewater, 16th ed., p. 532, American Public Health Association, 1985.

2) S. Ito and T. Yamaguchi, Nippon Kagaku Kaishi, 1991, in press.

3) JIS K 0102-1986.

4) The unit for the ordinate, volt multiplied by second, is arbitrary one, since the ordinate represents the numerical value of the integrated peak area, which is digitalized by the integrator used. 